\title{
EL NECROLOGIO DEL PADRE TEIXIDOR: DISPERSIÓN Y REUBICACIÓN DEL PATRIMONIO BIBLIOGRÁFICO DE LOS DOMINICOS VALENCIANOS DURANTE LOS SIGLOS XIX Y XX
}

\author{
POR \\ Miguel C. MuÑoz Feliu ${ }^{1}$ \\ Universitat Politècnica de València
}

\begin{abstract}
RESUMEN
Se estudian los avatares sufridos por el patrimonio bibliográfico de los dominicos valencianos durante los siglos XIX y XX a partir del seguimiento de cada uno de los cuatro volúmenes manuscritos del Necrologio del padre Teixidor: su primitiva ubicación en la librería del convento de Predicadores de Valencia, su traslado a las Baleares en la época napoleónica, su diverso destino en el periodo desamortizador, el retorno de varios volúmenes a manos de los religiosos tras la Restauración y las nuevas incautaciones y reubicaciones producidas durante y después de la guerra civil española.
\end{abstract}

PALABRAS CLAVE: José Teixidor (OP); Dominicos; Patrimonio Bibliográfico; Valencia.

\section{FATHER TEIXIDOR'S NECROLOGY: DISPERSION AND RELOCATION OF THE BIBLIOGRAPHIC HERITAGE OF THE VALENCIAN PREACHERS DURING $19^{\text {TH }}$ AND $20^{\text {TH }}$ CENTURIES}

\begin{abstract}
We study the itinerary suffered by the bibliographic heritage of the Valencian Dominicans during the nineteenth and twentieth centuries from the follow-up of each of the four manuscript volumes of father Teixidor's Necrology: its original location in the library of Santo Domingo de Valencia, its transfer to the Balearic Islands in the Napoleonic period, its different destiny in the period of the Ecclesiastical confiscation, the return of several volumes to the hands of the religious after the Restoration and the new seizures and relocations produced during and after the Spanish civil war.
\end{abstract}

KEY WORDS: José Teixidor (OP); Dominicans; Bibliographic Heritage; Valencia.

Cómo CITAR ESTE ARTículo / CitATION: Muñoz Feliu, Miguel C. 2019. «El Necrologio del padre Teixidor: dispersión y reubicación del patrimonio bibliográfico de los dominicos valencianos durante los siglos XIX y XX». Hispania Sacra 71, 144: 619-628. https:// doi.org/10.3989/hs.2019.044

$\begin{array}{ll}\text { Recibido/Received } & 03-07-2017 \\ \text { Aceptado/Accepted } & 31-10-2017\end{array}$

Es habitual encontrar en la historiografía amargas quejas de los efectos de las guerras y de los periodos revolucionarios sobre el patrimonio bibliográfico español. Durante el siglo XIX, la guerra de la Independencia y las desamortizaciones liberales habrían supuesto la pérdida de valiosos manuscritos e impresos atesorados en los conventos

\footnotetext{
1 mimufe@upvnet.upv.es / ORCID iD: https://orcid.org/0000-0002-6959-1086
}

y monasterios españoles. Unas calamidades que habrían tenido su triste continuación durante la guerra civil española, que supondría, tal como expresa Manuel de Castro citando el versículo de Joel 1:4, que «lo que dejó la oruga, lo comió la langosta». ${ }^{2}$ Sin embargo, pocas veces encontramos en dicha historiografía análisis detallados sobre casos concretos, cuantificaciones de dichas pérdidas o explicaciones 
que muestren el itinerario y reubicación de dicho patrimonio durante estos siglos. Tal y como señala García López, el panorama bibliográfico en la historia de las bibliotecas españolas sigue revelando importantes vacíos, especialmente por la falta de perspectivas innovadoras o por el escaso aprovechamiento de fuentes primarias. ${ }^{3}$

Este estudio pretende ayudar a llenar ese vacío, partiendo del seguimiento de una obra concreta, el Necrologio que escribiera el padre Teixidor durante el siglo XVIII. Formado por cuatro volúmenes, su carácter manuscrito e intencionadamente inédito ha hecho de dichos volúmenes objetos únicos, lo que facilita el seguimiento que pretendemos. Un itinerario que es buen ejemplo de los procesos de dispersión y reubicación sufrido por parte del patrimonio bibliográfico de los religiosos españoles a lo largo de los siglos XIX y XX.

\section{LA LIBRERÍA DEL CONVENTO DE PREDICADORES DE VALENCIA DURANTE LA ILUSTRACIÓN}

Uno de los conventos más importantes en la Valencia del siglo XVIII fue el convento de Santo Domingo, citado habitualmente en las fuentes de la época como convento de Predicadores. Fundado en el siglo XIII, este gran convento dominico disponía de casa de estudios y en él habitaban en 1778 más de un centenar de religiosos. ${ }^{4}$ Su producción intelectual fue muy notable. Fueron muchos los dominicos de este convento que jugaron un papel fundamental en la historiografía valenciana y figuras como Francisco Diago, Jacinto Segura, José Teixidor, Luis de Galiana, Luis Sales, Bartolomé Ribelles o Jaime Villanueva profesaron en él. ${ }^{5}$ Asimismo, entre los escritores valencianos que documenta Ximeno, los dominicos con 101 autores aparecen como la orden religiosa más prolífica. ${ }^{6}$

Por ello, no nos debe extrañar que la librería del convento de Predicadores fuera, en cantidad y en calidad, una de las más ricas de la ciudad de Valencia durante el Siglo de las Luces. ${ }^{7}$ Así lo atestiguan los inventarios e índices de su librería que realizara José Teixidor, quien fuera bibliotecario de este convento. ${ }^{8}$ Una riqueza que es también puesta de manifiesto por numerosos testimonios como el del bibliógrafo Ximeno cuando expresa que:

\footnotetext{
3 García López 2007: 195.

4 Así consta en el Informe presentado por el arzobispo Fabián y Fuero en la Santa Sede el 25 de septiembre de 1778 (Cfr. Cárcel Ortí 1986, T. II: 334).

5 Esponera Cerdán 1996.

6 Ximeno 1747-1749: índice III.

7 El término librería se utilizó hasta bien entrado el siglo XIX para referirse a «la biblioteca o conjunto de libros que tienen para su uso los cuerpos, o las personas particulares», mientras el término biblioteca en sentido estricto se aplicaría a «la que es muy numerosa y está destinada para el uso público» (Véase Real Academia Española. 1803. Diccionario de la lengua castellana: 130 y 515 . Madrid: por la viuda de Joaquín Ibarra). Tamaño y carácter público marcarían la diferenciación de estos dos vocablos, lo que también es visible en la terminología usada por las fuentes de la época que emplean el término librería para las colecciones bibliográficas de las comunidades religiosas, mientras que reservan el de bibliotecas cuando hablan de las nuevas bibliotecas públicas creadas por los gobiernos ilustrados primero, y por los liberales después.

8 La Universitat de Valencia conserva algunos de estos índices: Teixidor y Trilles 1747 y 1762 . Para una historia de su archivo y biblioteca,
} véase Callado Estela y Esponera Cerdán 2005.
El archivo, y librería del Real Convento de Santo Domingo de esta ciudad me ha socorrido muchíssimo, por el gran cuidado que han tenido los religiosos desde su fundación en continuar las memorias de sus escritores, y otros varones grandes que le han ilustrado, y en conservar sus manuscritos como también, porque su librería excede en el número de los libros a quantas ay en este reyno. ${ }^{9}$

Esta riqueza y cuidado son también puestos de relieve por Orellana, quien habla de «lo copioso de su exquisita librería». ${ }^{10} \mathrm{O}$ por Jaime Villanueva, buen conocedor de la misma por profesar en esa casa, que califica su librería como "un buen depósito de curiosidades literarias y tipográficas», con numerosos códices, muchos de tiempos medievales, ${ }^{11} \mathrm{y}$ donde también se encontraría el incunable Obres o Trobes en lahors de la Verge Maria, considerado entonces la primera obra impresa en España. ${ }^{12}$

Asimismo, hay numerosos testimonios sobre el uso y aprovechamiento de su librería por eruditos e intelectuales valencianos del siglo XVIII que recurrían a la misma para sus investigaciones. Entre ellos, el ilustrado Gregorio Mayans quien hizo uso de ella con frecuencia para estudiar ediciones o buscar textos originales. ${ }^{13}$ De hecho, autores como Antonio Ponz no dudaron en calificarla de «librería pública» establecida para "comodidad de los literatos». ${ }^{14}$

Fue precisamente a mediados de este siglo cuando nace el Necrologio de este Real Convento de Predicadores de Valencia: devidas memorias a sus hijos nativos con extensión en los más ilustres, recogidas de monumentos authénticos y seguros.

Su autor fue uno de sus más notables bibliotecarios e historiadores, José Teixidor y Trilles (Vila Nova del Grau de Valencia, 1694-Valencia, 1775). Teixidor se había formado en el colegio-universidad de Orihuela, donde conocería al padre dominico Jacinto Segura, quien le encaminaría hacia la investigación histórica. En sus primeros años sería archivero del convento de Predicadores, poniendo orden con tenacidad, rigor y conocimiento en un archivo hasta entonces poco utilizado, una labor que le permitió el contacto y manejo directo de las fuentes históricas. Tras una breve estancia en Orihuela, a partir de 1742 Teixidor se reincorporaría al convento de Predicadores de Valencia como archivero y bibliotecario desde cuyo puesto trataría con bibliógrafos e historiadores como Vicente Ximeno o Gregorio Mayans. En paralelo a esta labor, Teixidor inició una notable producción historiográfica, para lo cual no dudó en recorrer otros archivos y bibliotecas, transcribiendo y acumulando cuantos documentos caían en sus manos. Alfonso Esponera ha llegado a identificar 37 obras de Teixidor, que clasifica en tres grandes bloques o ejes: obras relativas a los dominicos; estudios sobre Valencia y sus instituciones, religiosas y civiles; y su correspondencia con respuestas a consultas. ${ }^{15}$

\footnotetext{
9 Ximeno 1747-1749: prefacio.

10 Orellana 1985-1987, Vol. 1: 526.

11 Villanueva 2001, carta XXXIII: 132-146.

12 Ibídem, carta XV: 113-114.

13 Así lo indica Antonio Mestre, el gran historiador de la figura de Mayans. Cfr.: Callado Estela y Esponera Cerdán 2005: 100.

14 Ponz 1972, Vol. IV, carta V: 100.

15 Esponera Cerdán 2009.
} 
Una de sus obras más notables es el Necrologio. Frente a la mayoría de libros de memorias o necrologios, casi siempre laudatorios para la institución o sus protagonistas y donde se utilizan como fuentes, al mismo nivel, tradición oral y testimonios escritos, este Necrologio es fruto de un historiador que vive en plena llustración y que basa todas sus aseveraciones en fuentes escritas, rechazando leyendas y noticias que no puedan ser comprobadas. De ahí su subtítulo, "recogidas de monumentos authénticos y seguros».

Pero, es más, la obra pretende ser tan rigurosa y completa, que, como prevención ante lo que pudiera allí aparecer en pro de la verdad histórica, se concibe como una obra manuscrita que debía permanecer inédita y de lectura solo para los miembros de la comunidad, tal como el propio Teixidor señala: «Digo que en lo que escriva nada disimularé, porque no aviendo de dar a la estampa este Necrologio, ni leerlo otros que los religiosos, no aparece inconveniente en que escriva las cosas como realmente passaron según prescriven las leyes de la historia». ${ }^{16}$

El Necrologio recogía centenares de biografías de los frailes que habían profesado en el convento de Predicadores de Valencia desde 1238 hasta 1776 . Se estructuraba en cuatro volúmenes, todos ellos en tamaño folio. El primer tomo comprendía las biografías de los dominicos que habitaron en dicho convento entre 1238 (fecha de la conquista cristiana de Valencia) y 1530. El tomo II abarcaba desde 1521 a 1599. El tercero, de 1600 a 1677. Y el tomo IV, desde 1678 hasta 1776. ${ }^{17}$ La biografía de Teixidor, realizada tras su muerte y añadida por otra mano, cierra el volumen IV. ${ }^{18}$

La obra, celosamente guardada por los dominicos, despertó mucho interés entre los coetáneos pues ofrecía datos de muy difícil consecución por otras vías. Así, en 1787 el obispo de Orihuela solicitaba copiar del Necrologio las vidas de los venerables Micó, Vidal, Bono y otras del marquesado de Albaida. La petición fue acogida favorablemente por los dominicos valencianos en el capítulo de 13 de abril de 1787 quienes autorizaron la salida de esta obra del convento, pero solo con el fin de que el escribiente pudiera hacer las copias con mayor comodidad y brevedad de tiempo; una vez acabadas las copias, la obra debía volver de inmediato a la librería conventual. ${ }^{19}$

\section{LA GUERRA DE LA INDEPENDENCIA: ENTRE LA PREVENCIÓN Y EL DESASTRE}

Entre 1808 y finales de 1811 la ciudad de Valencia y la mayor parte de su antiguo Reino seguirá en manos de los españoles y de las juntas surgidas tras el alzamiento contra los franceses en mayo de 1808. Los intentos de tomar la ciudad, como el de Moncey en junio de 1808, habían acabado en fracaso. Sin embargo, conforme se va desarrollando la guerra en otros lugares, se es cada vez más consciente de los riesgos que la contienda supone para los objetos más valiosos, entre los que se encuentran ciertos efectos

\footnotetext{
16 Teixidor, Necrologio: fol. 1. BUV. Ms. n. 931.

17 Actualmente, tres de los tomos están en la BUV: Ms. n.o 931 (T. I), Ms. n. 9932 (T.II) y Ms. n. 993 (T.IV). Se desconoce el paradero del Tomo III.

18 BUV. Ms. n.ㅇ 933, a partir de la p. 484.

19 AHN. Códices, L-554, fol. 131
}

artísticos y literarios, como códices, incunables o manuscritos. Ese riesgo afectaba a todo tipo de instituciones, pero en el caso de las comunidades religiosas adquiría aún mayor urgencia la adopción de medidas de salvaguarda, dado que era conocido que los franceses habían iniciado un proceso de supresión de conventos y monasterios en las zonas ocupadas. En ese contexto no es extraño que surjan planes y proyectos para poner a buen recaudo los efectos más valiosos que guardaban.

Algunas de estas iniciativas tendrán carácter institucional como es el caso de la propuesta que hace a principios de 1811 el fiscal Antonio Cano Manuel al Consejo de Regencia en Cádiz. La propuesta pretendía evacuar a las Baleares, islas que continuaban en poder de los españoles y que estaban protegidas por la armada inglesa, las preciosidades de las librerías y archivos valencianos, entre ellas las del convento de Predicadores. Un plan general de traslado de efectos científicos y artísticos que nunca se llevaría a término. ${ }^{20}$

Más suerte tuvieron las medidas que tomaron por su cuenta determinadas órdenes religiosas. Es el caso del convento de Predicadores de Valencia. En el capítulo de 11 de julio de 1811, los padres dominicos se hacen eco de la petición de la Junta Superior del Reino de Valencia en la que exhortaba a los valencianos a «extraer de la ciudad los tesoros y riquezas que tuvieran a fin de quitar este aliciente a los enemigos, cuyo carácter era la rapacidad, irreligión y violencia». Los padres dominicos deciden trasladar la plata a Ibiza, y guardar los papeles más relevantes de su archivo en el convento dominico de Llombai. Ahora bien, en el capítulo del 21 de julio, los padres corrigen esta última decisión por motivos tanto de seguridad, dado que Llombai era un pueblo abierto al que era más fácil entrar, como de índole práctica, pues era muy difícil conseguir bestias de carga en esa coyuntura. En vez de trasladar los documentos a Llombai, los dominicos deciden enviarlos a su convento de Palma de Mallorca. Y no solo los doce o trece cajones de documentos sino también «aquellos manuscritos y libros que a juicio del padre maestro bibliotecario fray Bartholomé Ribelles fuesen más apreciables en la librería». El embarque se produjo el 27 de julio; el cargamento constaba de 16 cajones que viajaron en un jabeque correo cuyo patrón era Bautista Miquel, y que llegaron a Mallorca el 6 de agosto de $1811 .{ }^{21}$

Conocemos los libros y manuscritos evacuados gracias a un inventario conservado en el actual Archivo de los Padres Dominicos de Valencia, publicado por Alfonso Esponera y Emilio Callado. El inventario recoge varios centenares de volúmenes, seguramente las obras consideradas más útiles o valiosas por los dominicos. Entre ellos, hay tanto documentos del archivo como de la librería. Entre los primeros, hay libros antiguos de actas capitulares, profesiones, títulos de propiedad y privilegios, pero también documentación reciente de censos y propiedades del convento. En cuanto a los volúmenes de biblioteca, la selección es amplia y variada, y abarca tanto impresos como manuscritos: obras de los Santos Padres, Biblias como las de Pagnino o Arias Montano, vidas de santos como la de san Vicente Ferrer que escribiera Teixidor, así como una amplia representación de temática histórica, campo en el que el convento de Santo Domingo era

\footnotetext{
20 Muñoz Feliu 2015: 120-122 y 406.

21 AHN. Códices, L554, sesiones de 11 de julio y 21 de julio de 1811.
} 
sobresaliente. No aparecen otras obras que, a juicio actual, tendrían un enorme valor como eran les Obres o Trobes en lahors de la Verge Maria, pero sí los cuatro volúmenes del Necrologio de Teixidor que viajaron en la caja n.․․ $3 .^{22}$

A finales de 1811 los franceses pusieron sitio a Valencia. Ante la resistencia ofrecida, la artillería francesa bombardeó duramente la ciudad el 7 de enero de 1812. Diversos relatos se hacen eco del desastre que es considerado de primera magnitud. Así, Laborde - en la edición realizada por Jaime Villanueva- nos indica que:

Valencia que era la Cariath-Sepher ${ }^{23}$ de España, perdió sus bibliotecas públicas, en solo un día, cuando los franceses la sitiaron y bombardearon en los principios de enero de 1812. Una granada incendiaria prendió fuego en la biblioteca arzobispal, que contaba más de 50.000 volúmenes, los que perecieron con el edificio y con los departamentos anexos de antigüedades romanas. Igual desgracia sufrió la de la Universidad, dádiva de Don Francisco Pérez Bayer, que gastó toda su vida, su saber y dinero en recogerla para honrar a su academia con la reunión de los libros más raros, más útiles, y de ediciones más escogidas. También perecieron en la misma época las bibliotecas preciosas de Santo Domingo, San Agustín y otros conventos, de las quales a duras penas se han podido recoger algunas miserables reliquias. ${ }^{24}$

Los daños ocasionados por el bombardeo no serían la única consecuencia de la ocupación francesa de Valencia. El 19 de enero de 1812, apenas una semana después de la ocupación, ya se habían dictado instrucciones sobre el modo de proceder a la incautación de los conventos y monasterios. Con presencia del prior o superior de la comunidad, los comisionados de Bienes Nacionales debían sellar «todas las puertas de la iglesia, librería, secretaría y demás puestos principales» quedando las llaves en poder de los mismos. Asimismo, el superior debía entregar un estado del número de religiosos, sus nombres y edad, así como un estado general de "todos los bienes, rentas y demás gracias» del convento o monasterio. Las autoridades militares auxiliarían en todas estas operaciones. ${ }^{25}$

El 22 de enero de 1812, se ordenaba la aplicación de la legislación desamortizadora bonapartista, con lo que quedaban suprimidas todas las órdenes religiosas de varones. En la ciudad, 18 conventos de religiosos fueron suprimidos y desposeídos de sus bienes, entre ellos el convento de Santo Domingo. ${ }^{26}$ Considerados enemigos declarados del gobierno afrancesado, 502 monjes y frailes serán enviados a Francia. 148 , demasiado viejos para soportar un viaje tan largo, quedarán reagrupados en varios lugares de Valencia y otros cinco serían fusilados. ${ }^{27}$ Todo ello supuso que los edificios

22 El documento se conserva en el Archivo Histórico del Real Colegio de Predicadores de Valencia, carpeta 6, Varia, s.n., y ha sido transcrito en el apéndice documental del artículo de Esponera Cerdán y Callado Estela 2003.

23 Ciudad bíblica de las letras y de los libros, llamada Dabir, de la tribu de Judá (Josué 15:6,7; Jueces 1:10-13).

24 Laborde 1816: 85-86. Esta edición al castellano es una traducción libre de la de 1809, y fue realizada, seguramente, por Jaime Villanueva, quien sería el autor real de este párrafo. Para esta última cuestión, véase Seguí, Romà. 2000.

25 ARV. Propiedades antiguas, legajos n. 0470.

26 Hernando Serra 2004: 106-107; Callado Estela 2009.

27 Bergerot 1986: 140 y 182. quedaron abandonados, con el consiguiente peligro para los bienes muebles que estos contenían, incluyendo impresos, manuscritos o pinturas. Por ello y para evitar el pillaje, el gobernador de Valencia, barón Robert, ordenó el 27 de enero de 1812 al ayuntamiento de Valencia la custodia del patrimonio histórico-artístico de las comunidades religiosas suprimidas, decidiendo este en una sesión celebrada ese mismo día reunir los libros de los conventos que habían quedado sin custodia junto con los que se habían podido salvar de la biblioteca universitaria en un mismo depósito, que quedó establecido en el Colegio de Corpus Christi. ${ }^{28}$ Asimismo, las autoridades bonapartistas, conscientes del ocultamiento de bienes por parte de las comunidades religiosas, intentaron por todos los medios que estos salieran a la luz. El 6 de febrero de 1812, el Diario de Valencia daba un plazo de 24 horas para que los vecinos y habitantes de la ciudad hicieran declaración en la oficina de la administración de la calle de Cabilleros, casa de Lorenzo Burriel, de cualquier clase de género o efectos pertenecientes a los conventos suprimidos. ${ }^{29}$

¿Qué hubieran hecho los franceses con los volúmenes de librería? Aquellos considerados útiles irían destinados a la biblioteca de la Universidad de Valencia, que había conseguido del mariscal Suchet la gracia de poder escoger los que quisieran de entre las librerías de los conventos de la ciudad. Una política que enlazaba con el deseo del gobierno de José I de establecer bibliotecas públicas en las principales ciudades españolas. ${ }^{30}$

La ocupación francesa de Valencia apenas duraría año y medio. Tras la marcha de los franceses, los liberales españoles constituyeron en julio de 1813 un nuevo ayuntamiento bajo la Constitución de 1812. Esta situación, sin embargo, no supuso el restablecimiento inmediato de las antiguas comunidades religiosas. Por un lado, muchos monjes y frailes seguían presos en Francia, mientras que otros habían muerto o habían huido de la ciudad. Por otro, los liberales no tenían prisa en proceder a devolverles sus bienes e inmuebles, pues estaba en su ánimo proceder a una reforma de los regulares que implicaba una reducción del número de conventos y monasterios. Solo se entregaron algunas casas, siempre en consonancia con esta proyectada reforma. No sería hasta después del golpe de Estado de mayo de 1814 y la vuelta al absolutismo, cuando las comunidades religiosas fueran plenamente restablecidas. Su restablecimiento implicó la recuperación de todos sus bienes, entre ellos, los volúmenes extraídos de sus librerías que fueron devueltos por la Universidad de Valencia en años posteriores. ${ }^{31}$

Sin embargo, la guerra había afectado gravemente a las comunidades religiosas. A las pérdidas derivadas de los hechos bélicos, hay que añadir el abandono de muchos conventos y monasterios, la reutilización del papel para la fabricación de cartuchos, o el expolio llevado a cabo por los ocupantes que trasladaron a Francia pinturas, incunables y manuscritos. En esa línea, el balance que hacen los cronistas de las órdenes religiosas es muy negativo. Rais y Navarro al tratar sobre el convento de Santo Domingo de Valencia relatan que:

\footnotetext{
28 AMV. Libro de Juntas de Abastos, F-87, fol. 94.

29 Hernando Serra 2004: 181.

30 Muñoz Feliu 2015: 137-146.

31 Ibídem: 160-161.
} 
De 25 a 30.000 volúmenes que se contaban en la librería común, apenas se habrá salvado la sexta parte; y casi nada de una vasta y rica colección de manuscritos y piezas inéditas, fruto de las vigilias de los muchos sabios que ha tenido esta casa desde su fundación. Lo mismo sucedió al archivo, que sin disputa era de los mejores o acaso el mejor de Valencia, por sus muchas noticias y antigüedades. No se salvó de él sino lo que con anticipación se envió a las islas. ${ }^{32}$

Similares consideraciones hacen en relación con otros conventos dominicos de la ciudad de Valencia como el de San Antonio y San Onofre: "De la biblioteca que era muy escogida, no han parecido sino algunas obras de poco mérito y estas truncadas». En cuanto al convento de Nuestra Señora del Pilar, Rais y Navarro señalan que, si bien los dominicos habían ocultado parte de sus bienes, incluyendo libros y documentos, en casas de particulares, estos, amedrentados por los franceses, los habían entregado a los mismos. ${ }^{33}$ Tampoco salieron mucho mejor parados los conventos femeninos de Santa María Magdalena y Nuestra Señora de Belén. ${ }^{34}$

Aunque seguramente los lamentos de los cronistas fueran exagerados, lo cierto es que las librerías de los religiosos no serían ya las mismas y que el eco de los destrozos en librerías y archivos conventuales durante la ocupación francesa seguiría resonando muchos años después. Cuando en 1835 y 1836 los comisionados gubernamentales entren en las mismas y procedan a incautar estos bienes, encontrarán que "sus librerías estaban ya incompletas por haber quedado a merced de los franceses en la Guerra de la Independencia». ${ }^{35}$

De momento, los cuatro volúmenes del Necrologio habían vuelto a Valencia desde las Baleares, ilesos, y se habrían reintegrado a una librería del convento de Santo Domingo menguada por los acontecimientos recientes.

\section{LA DESAMORTIZACIÓN DE MENDIZÁBAL}

Poco duraría la calma para las comunidades religiosas. Una nueva acometida desamortizadora tendría lugar durante el Trienio Liberal. Sin embargo, esta apenas afectaría al convento de Santo Domingo, salvo por la secularización de algunos de sus más célebres frailes como Jaime Villanueva. Frente a la supresión casi absoluta de las órdenes monásticas, las órdenes conventuales solo sufrieron una reducción en el número de los conventos y esta reducción no alcanzó al convento de Santo Domingo de Valencia. ${ }^{36}$ Sus bienes y propiedades permanecerían en poder de los dominicos. Su librería quedó intacta y sus volúmenes no serían objeto de incautación alguna, ni para su traslado a Madrid y posible incorporación a la Biblioteca Nacional Española de Cortes, ni para su integración en la nueva biblioteca pública proyectada por los liberales para la ciudad de Valencia. ${ }^{37}$

\footnotetext{
32 Rais y Navarro 1819: 236.

33 Ibídem: 241-244.

34 Callado Estela 2014: 145-156, 2015: 101-107.

35 ARV. Propiedades antiguas, legajo n.o 722, pliego 46.

36 España. Ley de 25 de octubre de 1820 de supresión de monasterios y conventos (Gaceta del Gobierno, n. 123, de 29 de octubre de 1820) y España. Real orden, de 21 de mayo de 1821, del Ministerio de Gracia y Justicia decidiendo sobre la reducción de conventos en la región de Valencia (Gaceta de Madrid, n. 186, 2 de julio de 1821).

37 Muñoz Feliu 2016.
}

No tendrían tanta suerte en la llamada Desamortización de Mendizábal. Entre agosto y septiembre de 1835 y en un contexto revolucionario, la práctica totalidad de conventos y monasterios valencianos de varones fueron cerrados por las juntas liberales, unas disposiciones que serían sancionadas posteriormente desde Madrid en un proceso que culminaría meses después con la supresión de la práctica totalidad de las órdenes religiosas de varones en toda España y una importante reducción de los conventos de monjas. ${ }^{38}$ Ese sería también el destino del convento de Santo Domingo de Valencia, que desde muy pronto quedó destinado a uso militar. ${ }^{39}$

Todos los bienes incautados quedaron destinados a la extinción de la deuda pública con unas pocas excepciones, entre las que se encontraban «los archivos, cuadros, libros y demás objetos pertenecientes a los institutos de ciencias y artes» que se aplicarían a «las bibliotecas provinciales, museos, academias y demás establecimientos de instrucción pública». ${ }^{40}$

Gracias a los inventarios realizados por los oficiales de la Comisión de Arbitrios de Amortización en el momento de la incautación sabemos que en la librería de Santo Domingo había un monetario que es descrito como «una colección de monedas viejas y modernas de cuarto y ochavos sin orden de explicación alguna ni índice». ${ }^{41}$ No contamos con una relación detallada de su librería en 1835 , pero sí disponemos de una estimación cuantitativa de la misma que arroja la cifra de 6.413 volúmenes. ${ }^{42}$

¿Llegaron esos 6.413 volúmenes a las bibliotecas provinciales? La respuesta es que solo una pequeña parte. Solo 1.546 volúmenes (un $24 \%$ ) pasarían en enero de 1837 a la Biblioteca de la Universidad de Valencia, entidad que había conseguido de la reina regente el privilegio de poder escoger aquellas obras de los conventos suprimidos que quisiera para sí y cuya biblioteca se convertiría en septiembre de 1838 en biblioteca pública, provincial y universitaria de Valencia. En comparación con otras librerías religiosas, la de Santo Domingo fue la que aportó un número mayor de volúmenes tanto en términos absolutos como en términos relativos en relación con el conjunto de su colección; seguramente, ello es indicador tanto de la riqueza como del aprecio de dicha librería por parte de las autoridades universitarias. ${ }^{43}$

Entre las obras seleccionadas, se hallaba "un libro de memorias del convento de Santo Domingo en folio y pasta», ${ }^{44}$ que bien podría corresponderse con uno de los volúmenes del Necrologio, concretamente con el tomo II que es el único que conservaba la Universidad Literaria de Valencia a principios del siglo XX cuando Gutiérrez del Caño cataloga sus manuscritos. De los otros tres, tal como escribía el propio Gutiérrez del Caño, la Universidad desconocía su paradero. ${ }^{45}$

38 Revuelta González 1976.

39 Gascón Pelegrí 1975.

40 España. Real Decreto, de 9 de marzo de 1836, de supresión de conventos y monasterios, art. 25 (Gaceta de Madrid n. 444, de 10 de marzo de 1836).

41 ARV. Clero, libro n.․ 4185, fol. 85.

42 ARV. Propiedades Antiguas, legajo n.o 722.

43 Muñoz Feliu 2015: 282-283.

44 BUV. Inventarios procedentes de conventos desamortizados, inventario de 4 de enero de 1837, fol. 1.

45 Gutiérrez del Caño 1913: ms. n.o 2259. 
¿Cómo desaparecieron los otros 4.867 volúmenes que constituían el $76 \%$ restante de la librería, así como los volúmenes I, III y IV del Necrologio? No lo podemos decir con certeza, pero sí debemos recordar el contexto en que se produce la incautación. La previsible supresión se veía venir en el horizonte tras la muerte de Fernando VII y los asaltos sufridos en 1834 por los conventos de Madrid y otras ciudades, con lo que es muy probable que los frailes ocultaran aquellos documentos que tuvieran especial significado para ellos, temiendo lo que se avecinaba. Tampoco debemos olvidar el abandono de los edificios tras la marcha de los religiosos cuyos efectos estuvieron meses y meses sin recoger a merced del robo y del pillaje, un hecho denunciado por los propios oficiales de Arbitrios de Amortización en 1836. Finalmente, recordemos que más de 50.000 volúmenes de los conventos y monasterios valencianos suprimidos fueron vendidos entre 1837 y 1839 por la comisión del Museo Provincial de Valencia, como medio de conseguir recursos con los que financiar la recogida y traslado de las pinturas y librerías desde otros puntos de la provincia. ${ }^{46}$

De hecho, la relatividad del éxito de la Universidad de Valencia en la recogida del patrimonio bibliográfico de conventos y monasterios fue puesta en cuestión desde muy pronto. Así, el francés Melchor Tirán, quien visita Valencia en 1842, recuerda el caso de los llamados Papeles varios, una colección miscelánea reunida por los dominicos valencianos formada por más de cien volúmenes que abarcaban todo tipo de materias, y de los cuales «la Biblioteca de la Universidad, heredera de varias de estas comunidades religiosas, no pudo recoger más de 26 volúmenes». ${ }^{47}$ Un porcentaje -uno de cada cuatro- similar a los volúmenes del Necrologio que habían pasado a la Universidad que conservaba solo el tomo II. A principios del siglo XX, nada se sabía de los tomos I, III y IV; aparentemente, se habían perdido en el proceso desamortizador.

\section{LA BIBLIOFILIA VALENCIANA DEL SIGLO XIX}

El siglo XIX fue una edad dorada para la bibliofilia, tanto en España como en Valencia. Bibliófilos valencianos como los Salvá, Juan Churat, Salvador Sastre o Serrano Morales formaron importantes colecciones bibliográficas de fondo antiguo durante esa centuria. ${ }^{48}$ No es casualidad que fuera precisamente durante este siglo cuando la bibliofilia alcanzara tanta notoriedad. Este fenómeno estuvo favorecido por el paso al mercado de grandes cantidades de objetos artísticos y literarios. En esa línea, historiadores como Nicolás Díaz Pérez ya habían señalado en 1885 la relación entre bibliofilia y desamortización. Para Díaz Pérez, «las bibliotecas de Salvá, de Gallardo, de Barrantes, del Duque de Osuna, del Marqués de Morante y del Conde de Torrejón, entre otras que pudiéramos citar, fueron las que más se enriquecieron con los libros de los conventos». ${ }^{49}$

Ahora bien, ¿cómo comprobar esta relación? Ello no es nada fácil por el tipo de coleccionismo practicado en este

\footnotetext{
46 Muñoz Feliu 2006: 138-139.

47 Paz Espeso 1913: 359.

48 Almela y Vives 1929. Para una visión en toda España, véase Almela y Vives 1949 o Sánchez Mariana 1993.

49 Díaz Pérez 1885: 154.
}

siglo. El historiador Vicente Igual hace una magistral descripción de los coleccionistas valencianos del siglo XIX y de su forma de proceder:

Los objetos de arte, barajados una y mil veces, ocupaban un lugar completamente distinto de aquel para el que fueron creados; y nadie sabía de dónde procedían, o si lo sabía no quería decirlo, o cambiaba su origen, y con ello la pista que condujese a conocer el autor, la fecha y el tema, todo lo cual quedaba al arbitrio del buen entendedor. Una catástrofe, en fin, para el arte valenciano; ni siquiera conocemos la historia anecdótica de aquel desastre, las grotescas incidencias, las grandes pequeñas estafas, los hallazgos insospechados, los frustrados negocios, porque todo se llevaba subrepticiamente, como un misterioso quehacer de contrabando; sus protagonistas, al ir desapareciendo del mundo de los vivos, dejaban en él sus ganancias o sus deudas, pero se llevaban, junto con sus vanidades y desengaños, el secreto de tantas aventuras y no pocas desventuras. ${ }^{50}$

Ciertamente, en la documentación conservada hay pocas pruebas que permitan verificar toda esta circulación y que nos permitan rastrear posibles relaciones entre la misma y las consecuencias de las desamortizaciones. Pero ello no quiere decir que no queden pistas o indicios.

Uno de dichos indicios puede ser la afortunada pervivencia de marcas de propiedad o signaturas que hayan sobrevivido a tachados, eliminación de hojas preliminares o lavados del papel. El examen, ya en el siglo XXI, de los volúmenes I y IV, del Necrologio nos revelan una parte de ese pasado ignoto. En el reverso de la cubierta de ambos volúmenes todavía existe una etiqueta que a modo de exlibris indicaba quien había sido su propietario. En la del tomo I pone: «De la librería del Dr. D. Vicente Gadea Orozco. Obra n.o 192. Vol. n. 422». Una etiqueta similar figura en el reverso de la cubierta del tomo IV con el texto: «De la librería del Dr. D. Vicente Gadea Orozco. Obra n.ㅇ 222. Vol. n.ㅇ 425». ${ }^{51}$

Vicente Gadea Orozco (Altea, 1841-Valencia,1904) había sido catedrático de Procedimientos y Práctica forense de la Universidad de Valencia. De convencidas ideas católicas y tradicionalistas, fue rector de la Universidad en diversos períodos coincidentes con gobiernos conservadores en Madrid: del 5 de septiembre de 1884 al 6 de diciembre de 1885; del 22 de noviembre de 1890 al 7 de enero de 1893; y del 6 de agosto de 1895 al 6 de diciembre de 1897. También fue decano del Colegio de Abogados de Valencia (elegido en 1886 y reelegido dos veces más) y senador en las legislaturas de 1889 a 1890 y de 1903 a 1904. Sería presidente de la Academia de la Juventud Católica de Valencia y en su condición de abogado asumió la defensa jurídica de intereses de la Iglesia Católica en importantes procesos judiciales. ${ }^{52}$ De hecho, gracias a sus servicios, León XIII le otorgaría el marquesado de Gadea Orozco, un título pontificio. ${ }^{53}$

Vicente Gadea Orozco tendría ocasión de adquirir ambos volúmenes del Necrologio en el último tercio del siglo XIX.

50 Igual Ubeda 1956: 69.

51 BUV. Ms. n.ㅇ 931 (T.I) y Ms. n. 933 (T.IV).

52 Diccionario de catedráticos españoles de derecho (1847-1943) [en línea]. Madrid: Universidad Carlos III de Madrid. Instituto Figuerola de Historia y Ciencias Sociales, 2011. Disponible en: <http://www.uc3m. es/diccionariodecatedraticos>

53 Rey 2017. 
Seguramente, su contenido era bien visto por una persona conservadora y religiosa como él, que procedió a incorporarlos en su colección. Allí permanecerían, seguramente en la villa que hizo construir en Altea conocida como Villa Gadea, hasta bien entrado el siglo XX. ${ }^{54}$

Otras pistas o indicios provienen de comentarios ocasionales relacionados con el uso de algún volumen. Gracias a una pista de este tipo, sabemos que el tomo III fue utilizado por Constantí Llombart hacia 1875 en su estudio preliminar a la edición de las poesías del Francesc Mulet, dominico del siglo XVII que habría profesado en el convento de Santo Domingo y cuya biografía habría sido incluida en el volumen III del Necrologio. Llombart respalda una de sus afirmaciones con la siguiente referencia: «obtingué per oposició, en maig de 1651, la càtedra de Arts de vesprés, segons diu lo erudit dominico P. Joseph Teixidor en lo tomo tercer del Necrologio que escrigué i del que habem pres moltes d'aquestes notes $"{ }^{55}$ Estos datos y otros le habrían sido facilitados por Josep M. Torres y por Francesc Vives, pero nada nos dice sobre dónde consultó este volumen concreto. ${ }^{56}$

\section{LA RESTAURACIÓN DE LOS DOMINICOS EN VALENCIA}

La Restauración borbónica de Alfonso XII abrirá un nuevo tiempo para la Iglesia católica en España, en el que esta recuperará gran parte de su influencia social perdida y acabará ejerciendo un papel preponderante en la educación. Ese peso vendrá acompañado por la instalación o reinstalación en España de numerosas órdenes religiosas, hasta el punto de que entre 1876 y 1900 serían autorizadas 34 congregaciones de varones. ${ }^{57}$ Valencia y su provincia no serían diferentes y en 1892 ya se habían establecido los franciscanos en Santo Espíritu y Ontinyent, los capuchinos en I'Olleria y Museros, los carmelitas en Valencia, los jesuitas en Valencia y Gandía o los dominicos en Valencia. ${ }^{58}$

El retorno de los religiosos estuvo acompañado de un intento de reconstitución de sus bibliotecas. Manuscritos e impresos ligados directamente a la orden serían buscados por los nuevos gestores para su incorporación a las mismas. Ello les llevaría a procurar recuperar los originales disponibles, muchos de los cuales habían sido ocultados, robados o vendidos a peso en tiempos de la Desamortización de Mendizábal. Para ello, los religiosos podían contar con el favor de una parte de la sociedad que les ayudaría con sus donaciones a recuperar libros y otros objetos de interés para ellos. Asimismo, los religiosos no dudarían en realizar copias manuscritas de otros volúmenes, cuyos originales eran de difícil consecución.

\footnotetext{
54 ídem.

55 Llombart 1876: 8.

56 Ibídem: 7, nota 1. Seguramente, las personas citadas son Francesc Vives Julià, archivero municipal de Valencia y padre de Vicent y de Francesc Vives i Liern, y Josep Maria Torres i Belda, archivero-bibliotecario del instituto de Castelló de la Plana (1862-1864) y de la Biblioteca Universitaria de Valencia que llegaría a dirigir entre 1883 y 1884 (Véase "Vives Liern, Vicent» y "Josep Maria Torres i Belda» en Diccionari enciclopèdic d'historiografia catalana [en línea]. Barcelona: Enciclopèdia Catalana [Consulta: 30-IV-2017]. Disponible en: <http:// enciclopedia. cat>). En todo caso, dicho volumen III no se hallaba ni halla ni en las bibliotecas donde trabajaron.

57 Castells 1973: 244.

58 Cárcel Ortí 1986, T. II: 651-652.
}

Así harán los dominicos tras su reinstauración en Valencia en 1892, quienes recuperarían libros y volúmenes manuscritos salvados por el joven fraile Sabas Galiana y ocultados en el convento dominico femenino de Santa Catalina de Siena. ${ }^{59}$ Con el tiempo esta reconstitución será notable, como prueba la identificación realizada por Alfonso Esponera y Emilio Callado de los documentos que los dominicos habían enviado a Mallorca en 1811. Como puede comprobarse, muchos de ellos han sido identificados con ejemplares obrantes en el actual Archivo Histórico del Real Convento de Predicadores de Valencia. ${ }^{60}$

Es en ese contexto en el que los dominicos recuperaron algunos de los volúmenes del Necrologio. El padre Celedonio Fuentes nos relata que «por una verdadera casualidad, me lo entregó, no hace mucho tiempo, una persona piadosa, que lo tenía en su poder, heredado de sus mayores». La obra impresa donde se incluye esta noticia es de 1930, así que los dominicos no debieron tener este volumen hasta la década de 1920. Celedonio Fuentes habla concretamente del tomo $\mathrm{IV}$, aunque es muy probable que los dominicos recibieran también el tomo I de las mismas manos. El donante debió ser un descendiente de Vicente Gadea Orozco quien había fallecido en 1905, y como él, un firme católico, "una persona piadosa» como lo define Celedonio Fuentes. ${ }^{61} \mathrm{Y}$ tal como sucede en las bibliotecas públicas actuales con las donaciones recibidas, los agradecidos dominicos mantuvieran los signos de su pasada propiedad en los volúmenes recuperados, que gracias a ello han llegado hasta hoy.

\section{REPÚBLICA Y GUERRA CIVIL}

Con la llegada de la II República, el anticlericalismo volvió a hacerse notar con fuerza. Por ello, los dominicos previsoramente ocultaron las piezas más valiosas de su archivo en Borriana, en domicilios de amigos y familiares. Gracias a ello, se salvaron del saqueo sufrido por el convento en mayo de 1931. En el bienio radical-cedista, la documentación volvería a Valencia. ${ }^{62}$

Desgraciadamente, la calma duraría poco. Con el triunfo del Frente Popular en febrero de 1936, el prior Vicente Montserrat hizo confeccionar dos inventarios. El primero es un inventario de reliquias. El segundo, titulado Distribución de los objetos del depósito y de los libros del archivo conventual de Predicadores de Valencia, recogía casi 300 volúmenes impresos y manuscritos, muchos de ellos originales de enorme valor histórico o simbólico; entre ellos, los volúmenes del Necrologio. ${ }^{63}$ La intención de estos inventarios era la de distribuir estos objetos en casas particulares y diversas instituciones, como así se produjo, y servir de guía para su recuperación posterior.

Por desgracia, los hechos subsiguientes serían mucho peores de lo que habían temido los dominicos. Tras el fracaso del golpe de Estado en Valencia y la llegada de un nuevo periodo revolucionario, numerosos frailes y sacerdotes fueron asesinados, sus conventos fueron ocupados y sus bienes incautados. Los libros de los religiosos, cuyo contenido era

\footnotetext{
59 Callado Estela y Esponera Cerdán 2005: 103.

60 Ibídem: 105-111.

61 Fuentes 1930: 13-14.

62 Callado Estela y Esponera Cerdán 2005: 103-104.

63 AHRCPV. Sección contemporánea
} 
por lo general muy poco valorado por los revolucionarios, se enfrentaron a diversos y graves peligros. En primer lugar, algunos archivos y bibliotecas sufrieron, especialmente durante el verano de 1936, asaltos e incendios. Pero, seguramente, el principal riesgo era el de ser reciclados: el papel era necesario para la intensa campaña propagandística que las autoridades republicanas estaban realizando como acompañamiento del esfuerzo bélico y que precisaba de carteles y folletos en masa; el pergamino podía servir como piel de tambor; y el plomo de los sellos, para fabricar balas. Afortunadamente, bibliófilos como Nicolau Primitiu GómezSerrano o archiveros como Felip Mateu i Llopis salvaron de las fábricas de papel cuantiosos y valiosos testimonios documentales. Así, solo entre el 19 de julio y el 4 de agosto de 1937, rescataron de las fábricas $4.500 \mathrm{~kg}$ de papel. ${ }^{64}$

Las obras incautadas o salvadas se fueron reuniendo en el Colegio de Corpus Christi bajo custodia de la Universidad de Valencia. Allí irían a parar el Archivo de la Catedral de Valencia junto con numerosas colecciones de las instituciones religiosas suprimidas o de personas particulares desafectas. ${ }^{65}$

¿Qué hubieran hecho las autoridades republicanas con los libros incautados? Aquellos considerados dignos de conservarse por su valor literario, bibliográfico e histórico irían destinados a la Biblioteca del País Valencià, una entidad constituida en febrero de 1937 que recuerda en su nombre y funciones a la Biblioteca de Catalunya. Los volúmenes duplicados o aquellas obras que no se considerasen útiles para los fines de dicha Biblioteca, irían destinados a otras bibliotecas de la región. ${ }^{66}$ Un posible aprovechamiento en la línea marcada por María Moliner y su plan de fomento de la lectura mediante la constitución de bibliotecas públicas. ${ }^{67}$

En todo caso, el triunfo de Franco abortaría rápidamente dichos planes. Se produce entonces la devolución de esos libros junto con otros muchos de dudosa procedencia. Algunos libreros se habían comprometido ante las autoridades a "no vender libros comprados en la dominación roja». Estas devoluciones, concentradas entre 1939 y 1942, se han materializado en centenares de expedientes de devolución de libros a entidades o particulares, incluyendo numerosas entidades religiosas. ${ }^{68}$

Los dominicos recibieron dos entregas. El 20 de septiembre de 1939, José M. a de Garganta recibía dos centenares de volúmenes de obras de manos de José M.a Ibarra Folgado, director de la biblioteca de la Universitat de València. Otra entrega de otra cincuentena de obras se produce el 5 de agosto de 1941 al prior del convento de Santo Domingo de Valencia, Marceliano de Llamera, procedentes de la librería de Plácido Cervera. En ninguna de dichas relaciones constan los volúmenes del Necrologio. ${ }^{69}$

Esa ausencia puede ser explicada por diversas razones. En primer lugar, los volúmenes del Necrologio carecían, tal como puede observarse hoy en día, de signos que indicaran que pertenecían a los dominicos. Su único símbolo de propiedad hacía referencia a Vicente García Orozco, un antiguo

\footnotetext{
64 Seguí i Francés 2006: 601-608.

65 Albiñana 2008: 67-68.

66 Ibídem: 610-611.

67 Faus 2000.

68 AUV. Biblioteca, cajas n. 036 y 37.

69 AUV. Biblioteca, caja n. 0 36, exp. B-36 y B-37.
}

rector de la Universidad de Valencia. En ese sentido, cabe recordar que, tal como se señalaba en los anuncios del Servicio de Recuperación Bibliográfica, la devolución a los legítimos poseedores debía ir corroborada por «firmas autógrafas, exlibris, iniciales, dedicatorias, sellos, etcétera» en los documentos demandados. Por otro lado, es muy probable que los dominicos que habían sufrido enormemente durante los tiempos de la guerra desconocieran su ubicación presente y simplemente dieran por perdidos esos y otros muchos volúmenes.

El proceso de devolución culminaría en 1942. En un aviso urgente, el Servicio de Recuperación Bibliográfica dio un plazo de 30 días para que los legítimos poseedores pasaran a recoger sus obras. "Transcurrido este plazo, y sin necesidad de nuevo aviso, las obras que no hayan sido retiradas por quienes se crean con derecho a ello, previa su justificación correspondiente, quedarán propiedad del Estado". ${ }^{70}$

Los volúmenes I y IV se unieron así al volumen II que ya estaba en manos de la Universidad de Valencia. Ahora bien, dado que la reorganización y catalogación de los manuscritos no se ha producido hasta tiempos muy recientes, las obras se han creído perdidas durante casi cincuenta años por los propios dominicos y por la comunidad científica y autores como Adolfo Robles seguía dándolos por desaparecidos en la década de $1980 .{ }^{71}$ Solo con la reordenación de la colección de manuscritos por parte de los técnicos de la Universitat de València a principios del siglo XXI, dichos manuscritos reaparecieron. ${ }^{72}$

\section{CONCLUSIONES}

Durante los últimos doscientos años, el patrimonio bibliográfico atesorado por las comunidades religiosas sufrió los avatares de tiempos convulsos para la sociedad en general, y para las órdenes religiosas en particular.

Es el caso de los cuatro volúmenes manuscritos del Necrologio del padre Teixidor que testimonian muy bien los procesos de ocultamiento, dispersión y reubicación que sufrió dicho patrimonio a lo largo de estos dos siglos.

Escrito en el siglo XVIII, el Necrologio, culminación de la mejor tradición historiográfica de los dominicos valencianos, estuvo ubicado inicialmente en la librería del convento de Predicadores de Valencia. El valor que le daba la comunidad hizo que fuera una de las obras que se trasladara a las Baleares, evitando el destino de otras muchas de las obras que permanecieron en la Valencia ocupada por Suchet. El Necrologio no tendría tanta suerte en tiempos de Mendizábal. En 1837, solo uno de los cuatro volúmenes, el tomo II, ingresaría la Biblioteca de la Universidad de Valencia. Los otros tres se "perdieron» en el proceso. Dos de ellos (los volúmenes I y IV) acabarían en manos de Vicente Gadea Orozco, uno de cuyos descendientes los donaría a la nueva biblioteca de los dominicos, retornados a Valencia

70 AUV. Biblioteca, caja n.o 37

71 Robles Sierra 1984: 401.

72 Hasta hace apenas unos años el único instrumento de descripción para conocer los manuscritos que guarda la Universitat de València ha sido el catálogo de Gutiérrez del Caño de 1913, donde solo consta el Tomo II del Necrologio. Incluso, hoy en día, los manuscritos siguen ausentes del OPAC de dicha biblioteca <http://trobes.uv.es>. 
tras la Restauración. La guerra civil española supuso una nueva incautación de la biblioteca de los dominicos. El ingreso de los tomos I y IV en la actual Biblioteca Histórica se produjo casi accidentalmente, ante la falta de una reclamación en tiempo y forma durante la posguerra. El tomo III, usado por Constantí Llombart en el siglo XIX, sigue todavía en paradero desconocido.

\section{FUENTES}

Siglas de bibliotecas y archivos:

ADPV: Archivo General y Fotográfico de la Diputación de Valencia

AHN: Archivo Histórico Nacional

AHRCPV: Archivo Histórico del Real Colegio de Predicadores de Valencia AMV: Archivo Municipal de València

ARV: Arxiu del Regne de València

AUV: Archivo Histórico de la Universitat de València

BUV: Biblioteca Històrica de la Universitat de València

Gutiérrez del Caño, Marcelino. 1913. Catálogo de los manuscritos existentes en la Biblioteca Universitaria de Valencia. Valencia: Librería Maraguat.

Laborde, Alexandre de. 1816. Itinerario descriptivo de las provincias de España y de sus islas y posesiones en el Mediterráneo. Valencia: Imprenta de lldefonso Mompié.

Rais, Mariano y Luis Navarro. 1819. Historia de la provincia de Aragón, Orden de Predicadores, desde el año 1808 hasta el de 1818. Zaragoza: por Francisco Magallón.

Teixidor y Trilles, José. 1747. Índice de los Sermones de tempore de todo el año, y de los sermones de assumptos raros. BUV. Ms. n. 8.

Teixidor y Trilles, José. 1762. Obras manuscritas i papeles varios, impressos i manuscritos. BUV. Ms. n.ㅇ 16.

Teixidor y Trilles, José. [Mediados del s. XVIII]. Necrologio de este Real Convento de Predicadores de Valencia: devidas memorias a sus hijos nativos con extensión en los más ilustres, recogidas de monumentos authénticos y seguros. BUV. Ms. n. 931 (T. I), Ms. n. 932 (T. II) y Ms. n. 933 (T. IV). Se desconoce el paradero del Tomo III.

Villanueva, Jaime. 2001. Viage literario a las Iglesias de España. Valencia: Faxímil Edicions Digitals y Biblioteca Valenciana. Edición digital facsimilar de la edición de Madrid: Imprenta de Fortanet, 1803-1852.

Ximeno, Vicente. 1747-1749. Escritores del reyno de Valencia chronológicamente ordenados. Valencia: en la Oficina de Joseph Estevan Dolz.

\section{BibLIOgRAFíA}

Albiñana, Salvador. 2008. «Requisados, raros y curiosos». En Libros en el infierno. La Biblioteca de la Universidad de Valencia, 1939. València: Universitat de València.

Almela y Vives, Francesc. 1929. Pomell de bibliòfils valencians. Castellón de la Plana: Sociedad Castellonense de Cultura.

Almela y Vives, Francesc. 1949. La bibliofilia en España. Valencia: Castalia.

Bergerot, Bernard. 1986. Le maréchal Suchet, duc d'Albuféra. Paris: Tallandier.

Callado Estela, Emilio. 2009. «Arte y parte del convento de Predicadores en la Guerra del Francés». En Actas del Congreso Internacional sobre la Guerra de la Independencia y los cambios institucionales, 489-508. Valencia: Diputación de Valencia.

Callado Estela, Emilio. 2014. Mujeres en clausura. El convento de Santa María Magdalena de Valencia. València: Universitat de València.

Callado Estela, Emilio. 2015. El paraíso que no fue. El convento de Nuestra Señora de Belén de Valencia. València: Universitat de València.

Callado Estela, Emilio y Alfonso Esponera Cerdán. 2005. «Aproximació històrica a l'arxiu i biblioteca del Reial Convent de Predicadors de València». En El Palau de la Saviesa: El Reial Convent de Predicadors de València i la Biblioteca Universitària, 97-113. València: Universitat de València.

Cárcel Ortí, Vicente. 1986. Historia de la Iglesia de Valencia. Valencia: Arzobispado.

Castells, José Manuel. 1973. Las asociaciones religiosas en la España contemporánea: un estudio jurídico-administrativo (1767-1965). Madrid: Taurus.

Castro y Castro, Manuel de. 1987. Bibliografía de las órdenes religiosas. Madrid: Fundación Universitaria Española.

Díaz Pérez, Nicolás. 1885. Las bibliotecas de España en sus relaciones con la educación popular y la instrucción pública. 2a ed. Madrid: Tipografía de Manuel G. Hernández.

Diccionari enciclopèdic d'historiografia catalana [en línea]. Barcelona: Enciclopèdia Catalana. [Consulta: 30-IV-2017]. Disponible en: $<$ http:// enciclopedia.cat>

Diccionario de catedráticos españoles de derecho (1847-1943) [en línea]. Madrid: Universidad Carlos III de Madrid. Instituto Figuerola de Historia y Ciencias Sociales, 2011. Disponible en: <http://www. uc3m.es/diccionariodecatedraticos>

España. Ley de 25 de octubre de 1820 de supresión de monasterios y conventos (Gaceta del Gobierno, n.․․ 123, de 29 de octubre de 1820).

España. Real Decreto, de 9 de marzo de 1836, de supresión de conventos y monasterios (Gaceta de Madrid n.o 444, de 10 de marzo de 1836).

España. Real Orden, de 21 de mayo de 1821, del Ministerio de Gracia y Justicia decidiendo sobre la reducción de conventos en la región de Valencia (Gaceta de Madrid, n. 186, 2 de julio de 1821).

Esponera Cerdán, Alfonso. 1996. «La Escuela Historiográfica del convento de Predicadores de Valencia en el siglo XVIII». En Actas del XVI Simposio Internacional de Teología de la Universidad de Navarra, 397-420. Pamplona: Universidad de Navarra.

Esponera Cerdán, Alfonso. 2009. «El historiador dominico fray José Teixidor». En Valencianos en la historia de la Iglesia III, coordinado por Emilio Callado Estela, 149-194. Valencia: Facultad de Teología San Vicente Ferrer.

Esponera Cerdán, Alfonso y Emilio Callado Estela. 2003. «Apuntamientos históricos sobre el actual Archivo Histórico del Real Convento de Predicadores de Valencia». Escritos del Vedat XXXIII: 369-388.

Faus, P. 2000. La lectura pública en España y el Plan de Bibliotecas de María Moliner. Madrid: ANABAD.

Fuentes, Celedonio. 1930. Escritores dominicos del Reino de Valencia. Valencia: Imprenta F. Ángeles Pitarch.

García López, Genaro Luis. 2007. «The current state of research on the history of public libraries in Spain». Library history 23 (3): 191-199. https://doi.org/10.1179/174581607×233823

Gascón Pelegrí, Vicente. 1975. El real monasterio de Santo Domingo, capitanía general de Valencia. Valencia: Caja de Ahorros y Monte de Piedad de Valencia.

Hernando Serra, María Pilar. 2004. El Ayuntamiento de Valencia y la invasión napoleónica. Valencia: Universitat de València.

Igual Ubeda, Antonio. 1956. Historiografía del arte valenciano. Valencia: Institución Alfonso el Magnánimo.

Llombart, Constantí. 1876. «Apunts biogràfichs del pare Francesch Mulet». En Obres festives compostes segons antiga i molt rahonable tradició, Francesc Mulet, 7-8. València: Llibreria d'En Francesch Aguilar.

Muñoz Feliu, Miguel C. 2006. «Liberalismo, desamortización y política bibliotecaria. El caso valenciano». Anales de Documentación 9: 133-141.

Muñoz Feliu, Miguel C. 2015. Bibliotecas y desamortización en la ciudad de Valencia (1812-1844). Tesis doctoral defendida en la Universitat de València.

Muñoz Feliu, Miguel C. 2016. «Liberalismo y bibliotecas. El proyecto de creación de una biblioteca pública en Valencia durante el Trienio Liberal». Revista General de Información y Documentación 26 (2): 555-581. 
Orellana, Marcos Antonio de. 1985-1987. Valencia antigua y moderna. Valencia: Librerías París-Valencia [Reprod. Facs. de: Valencia: Acción Bibliográfica Valenciana, 1923-1924].

Paz Espeso, Julián. 1913. "Los archivos y las bibliotecas de Valencia en 1842. Noticias de los mismos y trabajos verificados en ellos por Melchor Tirán». Revista de Archivos, Bibliotecas y Museos 17 (1112): 353-373.

Ponz, Antonio. 1972. Viaje de España. Madrid: Atlas.

Real Academia Española. 1803. Diccionario de la lengua castellana: 130 y 515 . Madrid: por la viuda de Joaquín Ibarra.

Revuelta González, Manuel. 1976. La exclaustración (1833-1840). Madrid: Biblioteca de Autores Cristianos.
Rey, Miguel del. 2017. «Casa Gadea» [en línea]. Altea blog. [Consulta: 28-5-2017]. Disponible en: <http://www.alteablog.com/blogs/ des-de-la-foia-dicard/casa-gadea>.

Robles Sierra, Adolfo. 1984. "Manuscritos del Archivo del Real Convento de Predicadores de Valencia». Escritos del Vedat XIV: 349-402.

Sánchez Mariana, Manuel. 1993. Bibliófilos españoles: desde sus orígenes hasta los albores del siglo XX. Madrid: Biblioteca Nacional y Ollero \& Ramos.

Seguí i Francès, Romà. 2000. «D’un episodi clandestí de Jaime Villanueva i del primer projecte editorial de Mariano de Cabrerizo». Métodos de Información 7 (37): 27-36.

Seguí i Francès, Romà. 2006. "La Biblioteca del País Valencià». Afers: fulls de recerca i pensament 21 (55): 601-629. 